\title{
Optimization of sympathectomy to treat palmar hyperhidrosis
}

\author{
G. Bischof - A. E. P. Cameron - C. Connery • \\ J. R. M. De Campos $\cdot$ M. Hashmonai • \\ P. B. Licht $\cdot$ C. H. Schick
}

Received: 2 January 2013/Accepted: 17 April 2013/Published online: 10 May 2013

(C) Springer Science+Business Media New York 2013

To the Editor,

We read with interest the article by Deng et al. [1] and compliment them for the important review they performed. This review, which includes articles from the last decade, comes to a conclusion regarding the best level of sympathetic ablation for the treatment of primary palmar hyperhidrosis shared by many authors (T3). However, in a thorough review (246 references) on the subject comparing the correlation of the method for sympathetic ablation with the subsequent occurrence of compensatory sweating [2], the authors could not define any such correlation.

G. Bischof $(\bowtie)$

Department of Surgery, St Josef Hospital, Vienna, Austria

e-mail: georg.bischof@sjk-wien.at

\section{A. E. P. Cameron}

Department of Surgery, The Ipswich Hospital, Ipswich, UK

C. Connery

Department of Surgery, St. Luke's-Roosvelt Hospital Center, New York, NY, USA

\section{J. R. M. De Campos}

Department of Thoracic Surgery, University of Sao Paolo, São Paulo, Brazil

\section{Hashmonai}

Faculty of Medicine, Technion-Israel Institute of Technology, Kesalsaba, Israel

\section{P. B. Licht}

Deparment of Cardiothoracic Surgery, Odense University Hospital, Odense, Denmark

C. H. Schick

German Hyperhidrosiscenter, Surgery Isar Clinics, Munich, Germany
In reviewing your study, we found that five articles for the period 2000-2006 were not included. These articles report the ablation of single ganglia [3-7]. Were there other similar omissions for the years 2007-2010? We would appreciate the comment of the authors about these omissions. Would the inclusion of these series in their study possibly change their conclusion?

Disclosures G. Bischof, A. E. P. Cameron, C. Connery, J. R. M. De Campos, M. Hashmonai, P. B. Licht, and C. H. Schick have no conflicts of interest or financial ties to disclose.

\section{References}

1. Deng B, Tan Q-Y, Jiang Y-G et al (2011) Optimization of sympathectomy to treat palmar hyperhidrosis: the systematic review and meta-analysis of studies published during the past decade. Surg Endosc 25:1893-1901

2. Kopelman D, Hashmonai M (2008) The correlation between the method of sympathetic ablation for palmar hyperhidrosis and the occurrence of compensatory hyperhidrosis: a review. World J Surg 32:2353-2356

3. Singh B, Shaik AS, Moodley J et al (2002) Limited thoracoscopic ganglionectomy for primary hyperhidrosis. S Afr J Surg 40:50-53

4. Reisfeld R, Nguyen R, Pnini A (2000) Endoscopic thoracic sympathectomy for treatment of essential hyperhidrosis syndrome: experience with 650 patients. Surg Laparosc Endosc Percutan Tech 10:5-10

5. Doolabh N, Horswell S, Williams M et al (2004) Thoracoscopic sympathectomy for hyperhidrosis: indications and results. Ann Thorac Surg 77:410-414

6. Atkinson JLD, Fealey RD (2003) Sympathotomy instead of sympathectomy for palmar hyperhidrosis: minimizing postoperative compensatory hyperhidrosis. Mayo Clin Proc 78:167-172

7. Goh PMY, Cheah W-K, da Costa M et al (2000) Needlescopic thoracic sympathectomy: treatment for palmar hyperhidrosis. Ann Thorac Surg 70:240-242 